13

\title{
Выход электронно-стимулированной десорбции и глубина проникновения возбуждающих электронов
}

\author{
() Ю.А. Кузнецов, М.Н. Лапушкин
}

Физико-технический институт им. А.Ф. Иофрфе РАН, Санкт-Петербург E-mail: kuznets@ms.ioffe.ru

Поступило в Редакцию 19 марта 2017 г.

Исследованы концентрационные зависимости электронно-стимулированной десорбции (ЭСД) атомов Cs и Na при адсорбции на неметаллических покрытиях, выращенных на W-подложке. Обнаружено, что процессы ЭСД происходят в интерфейсе адсорбированный слой-неметаллическая подложка. Показано, что спад в концентрационной зависимости выхода ЭСД, наблюдающийся после достижения монослойного покрытия, связан с уменьшением количества возбуждающих ЭСД электронов, достигающих интерфейса.

DOI: 10.21883/PJTF.2017.14.44827.16777

В настоящей работе проведено исследование поверхности методом электронно-стимулированной десорбции (ЭСД) [1]. Облучение поверхности твердого тела электронами с энергией больше порогового значения может вызывать десорбцию атомов и ионов с поверхности. ЭСД атомов и ионов происходит из диэлектрических образцов и полупроводников с адсорбированными на них металлическими пленками. Ранее было показано, что наличие ЭСД в адсорбционной системе служит прямым доказательством неметаллической природы такой системы [1].

ЭСД ранее успешно использовалась при исследовании адсорбции щелочных металлов (ЩМ) на различных металлических и полупроводниковых подложках, что позволило предложить модель ЭСД нейтральных частиц на основе оже-стимулированной десорбции и на ее основе интерпретировать полученные результаты по ЭСД атомов щелочных, щелочноземельных и редкоземельных металлов (РЗМ) с подложек различной природы [2-6]. В дальнейшем данная модель была модернизирована и детально проработана, а ее ключевым элементом стало наличие локального состояния вблизи дна зоны проводимости [7,8]. 
ЭСД атомов ЩМ и РЗМ как метод исследования адсорбционных систем и тонких пленок обладает высокой чувствительностью и к электронной структуре, и к адсорбционным состояниям исследуемых систем $[2-8]$.

ЭСД атомов характеризуется величиной выхода ЭСД $q$, равной отношению плотности десорбирующегося потока атомов к плотности потока электронов, возбуждающих ЭСД. Однако до сих пор не было уделено должного внимания влиянию толщины пленки адсорбата на выход ЭСД атомов и ионов. Глубина проникновения электронов, возбуждающих процесс ЭСД, очевидно, связана с длиной свободного пробега электронов в твердом теле. Данному вопросу посвящен ряд работ, как экспериментальных, так и теоретических, например $[9,10]$. Длина свободного пробега электронов в твердом теле $\lambda$ зависит от их кинетической энергии $E_{e}$. Зависимость $\lambda\left(E_{e}\right)$ имеет минимум в диапазоне $E_{e}=30-60 \mathrm{eV}$ и индивидуальна для каждого материала.

Целью настоящей работы является выяснить влияние глубины проникновения возбуждающих процесс ЭСД электронов на выход ЭСД атомов.

Для количества электронов $N$ с энергией $E_{e}$, проникших на глубину $d$, можно записать следующую формулу:

$$
N(d)=N_{0} \exp (-d /(\lambda \cos \gamma)),
$$

где $N_{0}$ - число падающих электронов на поверхность, $\gamma-$ угол падения электронов на поверхность относительно нормали к ней.

При ЭСД облучение электронами обычно производят в диапазоне $0-300 \mathrm{eV}$, но стоит отметить, что максимальный выход ЭСД на практике достигается при энергиях $20-100 \mathrm{eV}$.

Рассмотрим, как влияет толщина металлической пленки, адсорбированной на поверхности полупроводника, на выход ЭСД. Будем считать, что:

1) величина $\lambda$ остается неизменной для всех покрытий адсорбата, а возбуждение процесса ЭСД происходит по нормали к поверхности $(\gamma=0)$;

2) в процессе ЭСД принимает участие только ближайший к поверхности полупроводника слой металлического адсорбата;

3) вероятность возбуждения процесса ЭСД $p$ прямо пропорциональна покрытию вплоть до 1 монослоя (1 ML) и при больших покрытиях

6 Письма в ЖТФ, 2017, том 43, вып. 14 


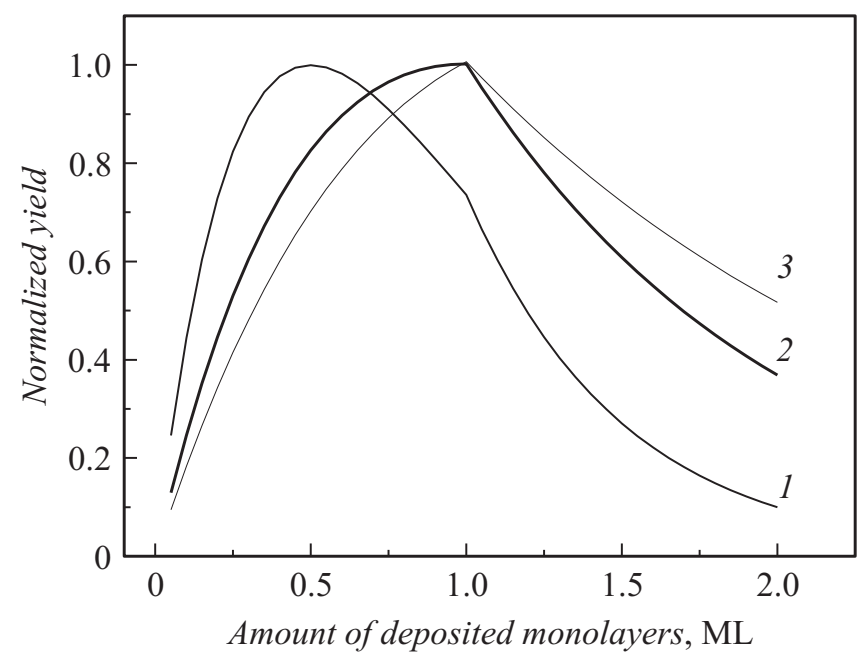

Рис. 1. Выход ЭСД $q$ в зависимости от толщины пленки адсорбата для трех значений длины свободного пробега $\lambda$, ML: $1-0.5,2-1.0,3-\lambda=1.3$.

остается неизменной. При этом второй слой адсорбата не принимает участия в процессе ЭСД;

4) выход ЭСД можно записать в виде $q=k N(d) p$, где $k-$ коэффициент пропорциональности.

На рис. 1 приведены расчеты в рамках простой модели выхода ЭСД $q$ в зависимости от толщины металлической пленки на поверхности полупроводникового адсорбата для трех значений $\lambda(0.5$, 1.0 и $1.3 \mathrm{ML})$. Величина $\lambda$ рассчитывалась в рамках модели TPP-2M [10]. Видно, что в рамках простой модели зависимость $q$ от покрытия имеет максимум. Возрастание $q$ связано с увеличением количества адсорбата вовлеченных в процесс ЭСД, а спад связан с процессом неупругих столкновений электронов, возбуждающих процесс ЭСД, в пленке адсорбата. Если $\lambda<1 \mathrm{ML}$, то максимум зависимости выхода ЭСД будет наблюдаться при покрытиях меньших $1 \mathrm{ML}$, а если $\lambda>1 \mathrm{ML}$, то максимум зависимости выхода ЭСД будет наблюдаться при покрытии 1 ML. Напыление же второго монослоя адсорбата приводит к резкому уменьшению выхода ЭСД.

Письма в ЖТФ, 2017, том 43, вып. 14 
Предлагаемые в настоящей работе исследования были проведены в сверхвысоковакуумной установке „Спектрометр ЭСД“. Прибор и методика измерений детально описаны ранее [7].

В качестве подложки исследуемых образцов использовались текстурированные W(100)-ленты, очищавшиеся прогревом при $1800 \mathrm{~K}$ в атмосфере кислорода при давлении $1 \cdot 10^{-6}$ Torr в течение $3 \mathrm{~h}$. Монослой кислорода наносился на ленту экспозицией в атмосфере кислорода при давлении $1 \cdot 10^{-6}$ Torr при $1600 \mathrm{~K}$ в течение $300 \mathrm{~s}$. Золото, цезий и натрий напылялись на ленту из соответствующих прямонакальных испарителей. Температура образца могла изменяться в диапазоне от 160 до $600 \mathrm{~K}$. Исследуемые образцы облучались пучком электронов с энергией в диапазоне $0-300 \mathrm{eV}$. Десорбирующиеся при этом атомы ионизировались на ленте поверхностной ионизации, а получаемый ионный сигнал усиливался с помощью электронного умножителя. Давление остаточных газов в установке не превышало $5 \cdot 10^{-10}$ Torr.

Установка „Спектрометр ЭСД“ позволяет регистрировать выход ЭСД атомов ЩМ с рекордной чувствительностью, измерять зависимость этого выхода ЭСД от энергии возбуждающих электронов, от количеств адсорбата и адсорбента, нанесенных на подложку, от температуры подложки, а также определять кинетическую энергию десорбирующихся атомов (по времени их пролета от образца до ионизатора) и ее энергораспределение.

На рис. 2 представлена экспериментальная зависимость выхода ЭСД атомов Cs от энергии возбуждающих электронов $E_{e}$, где хорошо видна квазирезонансная зависимость $q\left(E_{e}\right)$ для системы $\mathrm{Cs} / \mathrm{Cs} \mathrm{Au} / \mathrm{Au} / \mathrm{W}$. Детально процессы, приводящие к формированию пика $q\left(E_{e}\right)$, рассмотрены в [7,8]. На рис. 3 представлены зависимости выхода $q$ атомов ЩМ при ЭСД с вольфрама, покрытого двумя монослоями золота, от количества напыленного ЩМ при энергии возбуждения электронов $64 \mathrm{eV}$, в максимуме квазирезонансного пика $q\left(E_{e}\right)$. Необходимость напыления двух монослоев Аu связана с особенностями формирования полупроводникового интерметаллида ЩМ-золото [11]. Так, ближайший к $\mathrm{W}$-подложке монослой $\mathrm{Au}$ не принимает участия в формировании интерметаллида, в его образовании принимают участие верхние слои $\mathrm{Au}$. При напылении первого монослоя атомов ЩМ на $\mathrm{Au}$ образуется слой адсорбированных атомов ЩМ. Дальнейшее же напыление атомов ЩМ приводит к формированию полупроводникового интерметаллида ЩМ-золото [11-13] и появлению ЭСД атомов ЩМ.

$6^{*}$ Письма в ЖТФ, 2017, том 43, вып. 14 


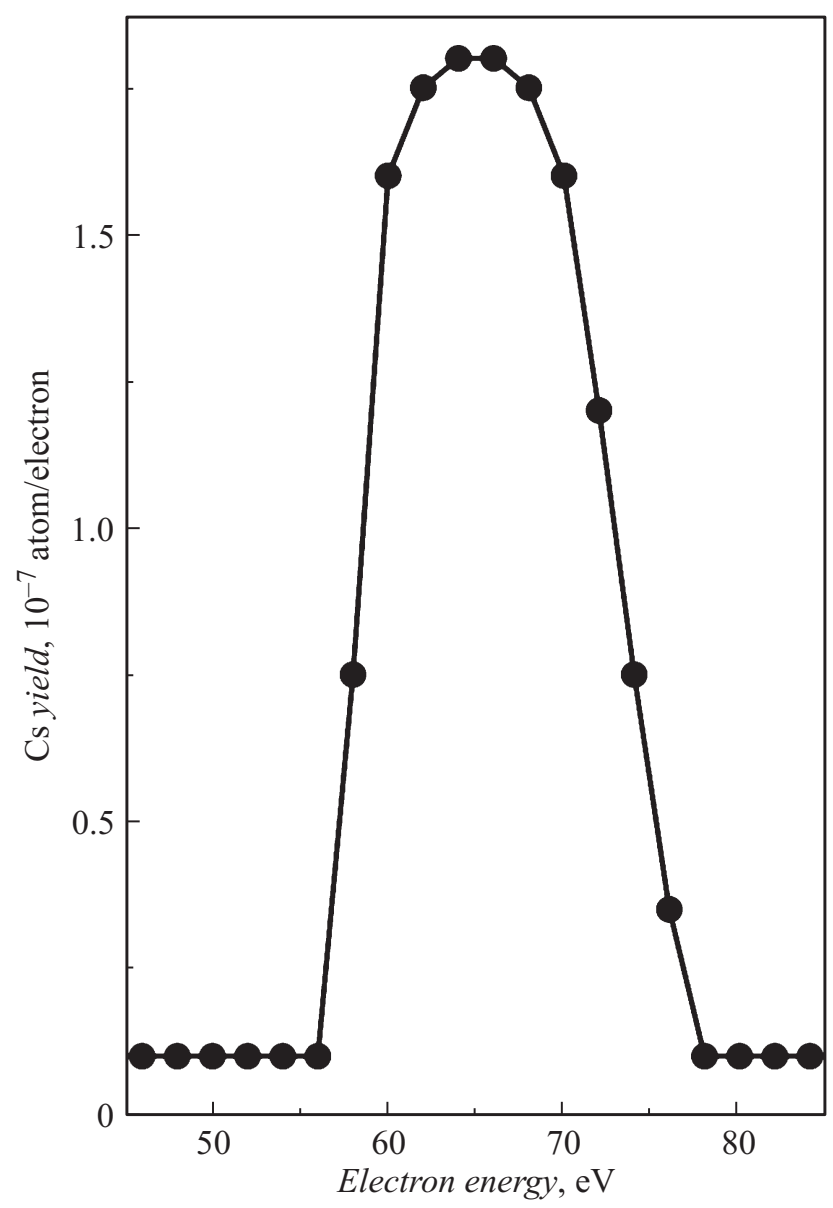

Рис. 2. Выход ЭСД $q$ атомов Сs при ЭСД с вольфрама, покрытого при $300 \mathrm{~K}$ двумя монослоями золота и двумя монослоями цезия, для $T=160 \mathrm{~K}$ в зависимости от энергии бомбардирующих электронов $E_{e}$.

Наблюдается практически линейный рост выхода ЭСД с увеличением покрытия атомов ЩМ. После достижения максимума при напылении двух монослоев ЩМ выход ЭСД уменьшается. При этом выход ЭСД

Письма в ЖТФ, 2017, том 43, вып. 14 

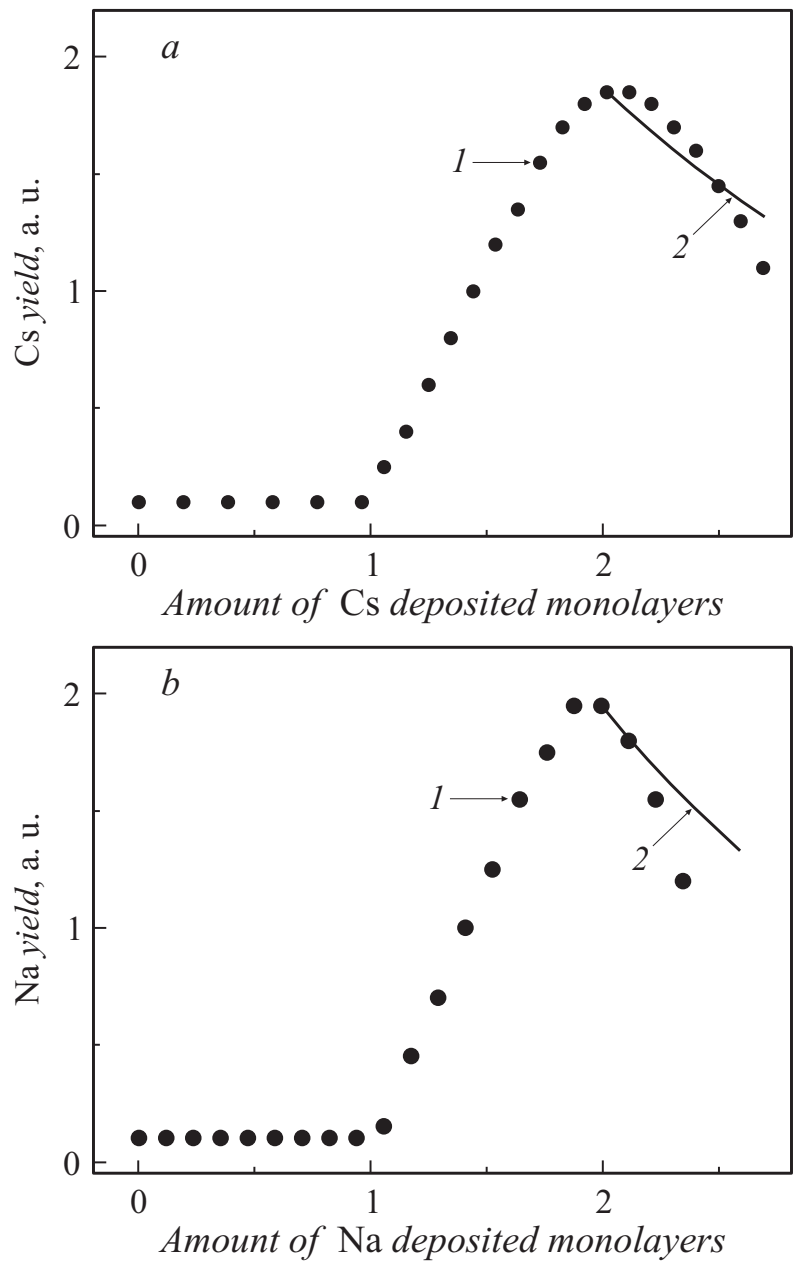

Рис. 3. Экспериментальные (1) и рассчитанные (2) значения выхода атомов $\mathrm{Cs}(a)$ и $\mathrm{Na}(b)$ при ЭСД с вольфрама, покрытого при $300 \mathrm{~K}$ двумя монослоями $\mathrm{Au}$, для $160 \mathrm{~K}$ в зависимости от количества напыленного ЩМ. Энергия электронов $64 \mathrm{eV}$.

Письма в ЖТФ, 2017, том 43, вып. 14 
не зависит от толщины соединения ЩМ-золото [14], что указывает на участие в ЭСД адатомов ЩМ на сформированной полупроводниковой пленке интерметаллида ЩМ-золото, либо из ближайшего к интерметаллиду слоя ЩМ, т. е. процесс возбуждения ЭСД происходит в интерфейсе металл-полупроводник [8]. Диффузия же десорбирующихся атомов ЩМ сквозь верхний монослой ЩМ маловероятна, так как такой процесс возможен только при наличии существенного количества дефектов в верхнем монослое ЩМ.

Оценим величину уменьшения выхода ЭСД с учетом того, что с увеличением толщины адсорбированного слоя ЩМ количество электронов, возбуждающих процесс ЭСД, происходящий в интерфейсе полупроводник-металл, уменьшается за счет неупругого рассеяния в адслое ЩМ. Будем считать, что толщина одного монослоя ЩМ равна диаметру атома ЩМ, т. е. для цезия толщина $1 \mathrm{ML}$ равна $0.53 \mathrm{~nm}$, а для натрия толщина монослоя будет равна $0.38 \mathrm{~nm}$. Также делаются те же предположения, что и ранее при расчете теоретического выхода ЭСД при напылении металлической пленки на поверхность полупроводника. Отметим, что в этом расчете формирование полупроводника происходит только при напылении второго монослоя ЩМ, когда на его поверхности уже есть $1 \mathrm{ML}$ ЩМ. Поэтому в этом случае ЭСД появляется после напыления одного монослоя ЩМ, а не сразу, как на рис. 1. Вероятность возбуждения процесса ЭСД в диапазоне доз напыления ЩМ от 1 до 2 ML прямо пропорциональна количеству сформированного интерметаллида, а при больших дозах напыления ЩМ ( $>2 \mathrm{ML})$ остается неизменной.

Глубина проникновения $\lambda=1.03 \mathrm{~nm}$ в слое Cs рассчитана в рамках модели ТРР-2М [10], так как экспериментальных значений $\lambda$ для данных энергий электронов найти не удалось. Расчет проводился только для доз напыления больших двух монослоев, когда толщина адсорбированных пленок ЩМ увеличивается. Получено хорошее согласие экспериментальных и рассчитанных значений (рис. $3, a$ ).

Аналогичный расчет был сделан и для адсорбции $\mathrm{Na}$ (глубина проникновения $\lambda=0.60 \mathrm{~nm}$ ), который приведен на рис. $3, b$. Экспериментальные и рассчитанные значения совпадают хуже, чем в случае адсорбции Cs. Наблюдаемые расхождения между экспериментальными и рассчитанными значениями могут быть связаны как с заниженными значениями $\lambda$, которые получаются в рамках модели ТРР-2М [10], так

Письма в ЖТФ, 2017, том 43, вып. 14 
и, возможно, с уменьшением вероятности возбуждения процесса ЭСД в интерфейсе $\mathrm{Na} / \mathrm{NaAu}$.

Исследованы концентрационные зависимости выхода ЭСД атомов Cs и $\mathrm{Na}$ на различных подложках $\mathrm{CsAu}$ и $\mathrm{NaAu}$, и показано, что эти зависимости отражают особенности формирования $\mathrm{Cs} / \mathrm{CsAu}$ и $\mathrm{Na} / \mathrm{NaAu}$ на $\mathrm{Au} / \mathrm{W}$. Процессы ЭСД происходят в интерфейсе адсорбированный слой-неметаллическая подложка. Продемонстрирована роль глубины проникновения возбуждающих процесс ЭСД электронов. Наблюдаемые расхождения между экспериментальными и рассчитанными кривыми могут быть связаны с влиянием процессов изменения взаимодействия в интерфейсе адсорбированный слой-неметаллическая подложка, которые приводят к изменению электронной структуры в интерфейсе, что в свою очередь ведет к уменьшению вероятности процесса ЭСД, либо с уменьшением прозрачности второго слоя для выхода атомов, участвующих в процессе ЭСД.

\section{Список литературы}

[1] Ageev V.N. // Progr. Surf. Sci. 1994. V. 47. P. 55.

[2] Ageev V.N., Kuznetsov Yu.A., Potekhina N.D. // J. Phys.: Condens Matter. 2010. V. 22. P. 084005.

[3] Агеев В.Н., Кузнецов Ю.А., Потехина Н.Д. // ЖТФ. 2013. Т. 83. С. 85.

[4] Ageev V.N., Kuznetsov Yu.A., Potekhina N.D. // Surf. Sci. 1996. V. 367. P. 113.

[5] Ageev V.N., Kuznetsov Yu.A. // Phys. Low-Dim. Struct. 1999. N 1/2. P. 113.

[6] Ageev V.N., Kuznetsov Yu.A., Madey T.E. // Surf. Sci. 2006. V. 600. P. 2163.

[7] Кузнецов Ю.А., Лапушкин М.Н. // Физико-химические аспекты изучения кластеров, наноструктур и наноматериалов. Тверь: Твер. гос. ун-т, 2015. B. 7. C. 333.

[8] Кузнецов Ю.А., Лапушкин М.Н., Потехина Н.Д. // Письма в ЖТФ. 2016. T. 42. B. 12. C. 14.

[9] Lindau I., Spicer W.E. // J. Electr. Spectr. Relat. Phen. 1974. V. 3. P. 409.

[10] Tanami S., Powell C.J., Penn D.R. // Surf. Interf. Anal. 2015. V. 47. P. 871.

[11] Агеев В.Н., АЯанасьева Е.Ю. // ФТТ. 2006. Т. 48. С. 2217.

[12] Barth J.V., Behm R.J., Ertl G. // Surf. Sci. 1995. V. 341. P. 62.

[13] Кнатько М.В., Лапушкин М.Н., Палеев В.И. // ЖТФ. 1998. Т. 68. С. 108.

[14] Агеев В.Н., Кузнецов Ю.А., Потехина Н.Д. // ФТТ. 2010. Т. 52. С. 1828.

Письма в ЖТФ, 2017, том 43, вып. 14 